\title{
Research into Silicon Nanoparticles as Agents for UHF Hyperthermia In Vitro
}

\author{
Angelina V. Kosheleva* and Egor A. Bobkov \\ National Research Nuclear University «Moscow Engineering Physics Institute», 31 Kashirskoe shosse, Moscow, \\ Russian Federation
}

* e-mail: anjelickos-2013@yandex.ru

\begin{abstract}
The current approaches to cancer treatment, including surgery and high-energy beam irradiation, do not always give satisfactory results for a number of oncological neoplasms. One of the promising areas in oncology is the use of nanoparticles selectively heated by external action as agents for hyperthermia of some types of tumors. In this work, we performed selective heating of suspensions of silicon nanoparticles using a device for electromagnetic high-frequency therapy (UHF-60). (C) 2021 Journal of Biomedical Photonics \& Engineering.
\end{abstract}

Keywords: microporous silicon nanoparticles; cancer therapy; highfrequency hyperthermia.

Paper \#3385 received 25 Nov 2020; revised manuscript received 2 Mar 2021; accepted for publication 23 Mar 2021; published online 31 Mar 2021. doi: 10.18287/JBPE21.07.010306.

\section{Introduction}

In the modern world, the problem of an increase in the number of patients with various types of oncological diseases is quite acute. According to statistics, physicians register about 10 million new cases of the disease annually in the world. Current approaches to cancer treatment, including surgery, high-energy beam irradiation and chemotherapy, do not always give satisfactory results for a number of cancers. That is why the search for new directions and methods of cancer therapy is now a trending topic. One of the promising areas in oncology is the use of nanoparticles as a means of both diagnostics and cancer therapy [1].

It is assumed that with the help of nanoparticles (NPs), the problems of early diagnosis of malignant neoplasms, determination of their localization, targeted delivery of drugs into the tumor can be solved, and new methods of therapy can also be developed [2]. It has been shown that some types of inorganic particles are able to selectively accumulate in tumor tissues due to the enhanced permeation and retention effect (EPR) [3] associated with the particle size. At the same time, NPs for biomedical applications should be non-toxic, biocompatible, and naturally excreted from the body [4].

Hyperthermia is one of the methods of treating oncological diseases. The essence of this method is to heat the human body to a temperature over $41^{\circ} \mathrm{C}$. At this temperature, cancer cell can die [5]. However, the selectivity of this method needs to be increased to minimize the accompanying damage to healthy tissues. Therefore, despite its apparent simplicity, this method is fraught with a lot of risks and complexity in execution. When using hyperthermia, the method of local hyperthermia brings the least harm to the body. This is heating only a narrowly localized area affected by cancer cells. Since tissue heating is supposed to be carried out by means of high-frequency or laser radiation, it is necessary to use such NPs, which, in addition to their low toxicity, will be heated under the influence of these types of electromagnetic radiation. In this work, we used silicon (Si) based NPs. The properties of this type of NP have been studied by many scientists and researchers for quite a long time [6]. The article by L. Osminkina and V. Timoshenko "Porous Silicon as a Sensitizer for Biomedical Applications" implies that silicon particles can be used as sensitizers for UHF hyperthermia [7].

It is assumed that microporous silicon NPs ( $\mu$ Psi) accumulated in cancer cells will heat up more than healthy tissues of the body. Thus, the plan is to carry out the destruction of cancer cells without affecting the adjacent healthy ones. This method will make the therapy of cancer safe and effective. Therefore, the aim of this work is to study the rate and maximum temperature of heating of aqueous suspensions of NPs $\mu$ Psi under RF excitation.

High-frequency radiation has a large penetration depth, which makes it possible to treat deeply located tumors. Physical experiments show that heating of aqueous suspensions of PSi NPs by tens of centigrade can 
be achieved by irradiation at a frequency of $27 \mathrm{MHz}$ and a relatively low intensity $\left(1-5 \mathrm{~W} / \mathrm{cm}^{2}\right)$ [8].

Thus, it is possible to reach the solution temperature above $41{ }^{\circ} \mathrm{C}$. The purpose of the experiments is to select the most convenient heating method, as well as to select the correct concentration of nanoparticles. The higher the concentration of PSi NPs, the stronger the heating of its solution. However, silicon still has a slight toxicity, and therefore it is necessary to select the most effective and least harmful concentration of the PSi NP solution for the body.

\section{Synthesis and Characterization of Porous Silicon Nanoparticles}

Porous silicon (PSi) is a non-toxic, biocompatible and biodegradable material (Fig. 1). It is able to activate (sensitize) biochemical reactions and physical processes of energy dissipation when excited (irritated) by light and high-frequency radiation [7].

Microporous silicon (micro-PSi) samples were formed by the standard method of electrochemical etching [9] of bulk cSi wafers (p-type, doped with boron to a resistivity of $1-10 \mathrm{Ohm}-\mathrm{cm},(100)$-oriented) in a mixture of hydrofluoric acid (48\%) and ethanol (1:1).

The etching time was 40 min with the current density of $60 \mathrm{~mA} / \mathrm{cm}^{2}$. Free standing PSi films were obtained by removing from the substrate after applying a short pulse of etching current of $500 \mathrm{~mA} / \mathrm{cm}^{2}$. In previous studies, PS films were dried in air for 1 week. Mesoporous silicon (meso-PSi) samples were obtained from p-type c-Si wafers heavily doped with boron (the resistivity is $1-$ $5 \mathrm{Ohm}-\mathrm{cm}$, the orientation is (100)) using the same electrochemical etching procedure.

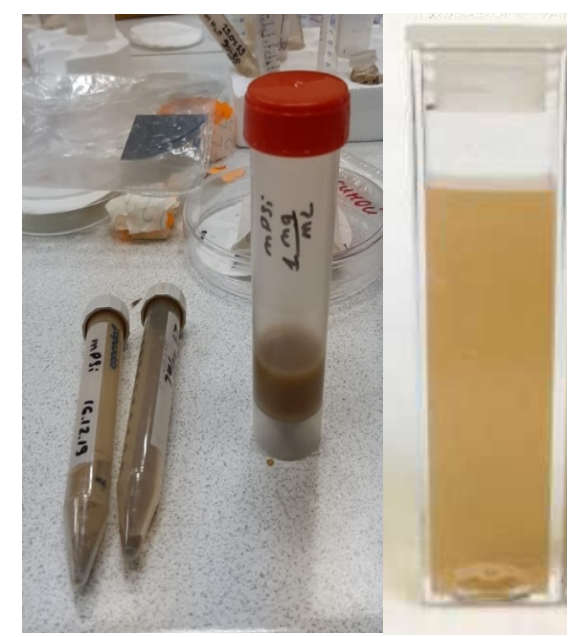

Fig. 1 Microporous silicon nanoparticles.

To study the stability of Si nanoparticles in water, the respective powders were suspended in water. $200 \mathrm{mg}$ of meso-PSi and micro-PSi powders were ground in $2 \mathrm{ml}$ of water for $2 \mathrm{~min}$ in a planetary mill (PULVERISETTE 7, "FRITSCH", Germany), $\mathrm{ZrO}_{2}$ balls $5 \mathrm{~mm}, 2 \mathrm{~min}$, $900 \mathrm{rpm})$ or in an aqueous solution of dextran (30-40 kDa), $10 \mathrm{wt} \%$ ). The suspensions were dried on cover slips immediately after grinding, 48 and $120 \mathrm{~h}$ after grinding.

The phase purity of the compounds was checked by powder X-ray diffraction (XRD) recorded on a RADIAN-DR2 (ZAO “STC Expert Center", Moscow) diffractometer $(\mathrm{CuKa} 1$ radiation, image resolution is 0.05 for panoramic scanning, 0.01 for scanning the peak shape, the exposure time is $1 \mathrm{~s}$ for panoramic scanning, $20 \mathrm{~s}$ for scanning the peak shape).

Fig. 2 shows a $\mu$ Psi image obtained using a LEO912 AB OMEGA transmission electron microscope located at Moscow State University [10].

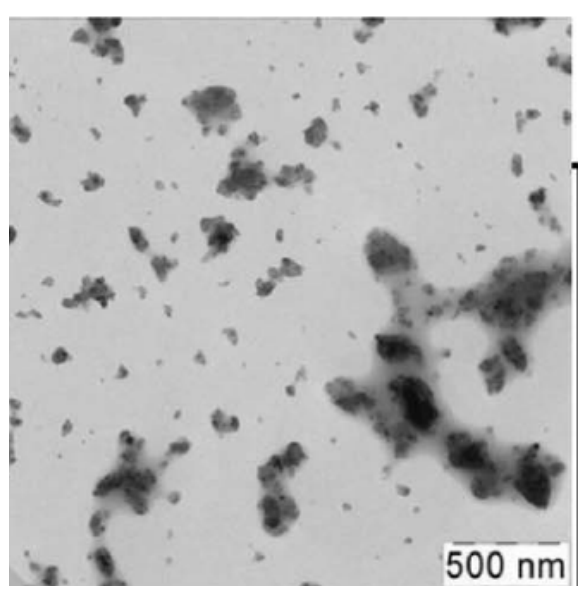

Fig. $2 \mu$ Psi Nanoparticles under LEO912 AB OMEGA ("Carl Zeiss", Germany) transmission electron microscope.

\section{Study into Heating Colloids under UHF Excitation}

HF heating in each experiment was carried out by means of the UHF-60-MedTeKo ("MedTeKo LLC", Russia) UHF-therapy apparatus operating at a frequency of $27.12 \pm 0.16 \mathrm{MHz}$ with a maximum power of $60 \mathrm{~W}$. The temperature was controlled by means of a Flir C3 ("Flir", USA) thermal imager. The heating power was $60 \mathrm{~W}$ with the thermal imager measured temperature in the range from $-10{ }^{\circ} \mathrm{C}$ to $+150^{\circ} \mathrm{C}$. The measurement error was 1 degree or $1 \%$ depending on the value.

To measure heating, three $4.5 \mathrm{ml}$ polystyrene cuvettes were filled with aqueous solutions with nanoparticle concentrations of $3 \mathrm{~g} / \mathrm{l}, 6 \mathrm{~g} / \mathrm{l}$, and distilled water in the third cuvette. The volume of each solution was $1.5 \mathrm{ml}$. Once the solutions had been prepared, the flask was positioned in the center between the RF electrodes, spaced $42 \mathrm{~mm}$ apart, providing an air gap of approximately $6 \mathrm{~mm}$ on both sides of the cuvette (Fig. 3).

$200 \mu \mathrm{l}$ of the solution of silicon nanoparticles with the concentration of $15 \mathrm{mg} / \mathrm{ml}$ was prepared for subsequent introduction into beef liver. The liver was placed between the electrodes of the UHF-therapy apparatus on a plastic Petri dish. 


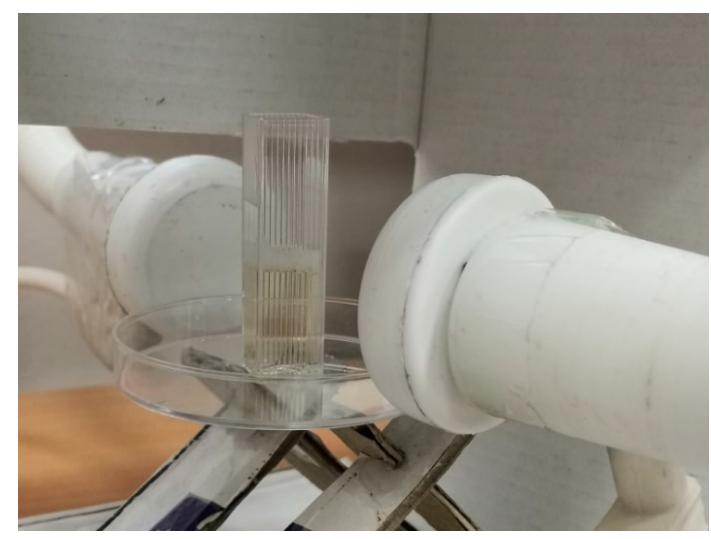

Fig. 3 Installation of a cuvette between the electrodes of the UHF-therapy apparatus.

\subsection{Determination of heating value of microporous silicon aqueous suspension when exposed to $\mathrm{HF}$ radiation $(27 \mathrm{MHz}$ )}

In this experiment we used solutions of microporous silicon ( $\mu \mathrm{PSi}$ ) with a concentration of $6 \mathrm{~g} / 1$ and $3 \mathrm{~g} / \mathrm{l}$, as well as distilled water. Each sample was heated for $5 \mathrm{~min}$. The purpose of the experiment was to establish the relationship between the sample temperature growth rate and the time for several concentrations of microporous silicon particles. This is enough to take solutions with the concentration of low-frequency PE, which will differ by a factor of two, for the clarity of the experiment. These figures are not related to the effective dose for the human body. The initial conditions were at room temperature of $19^{\circ} \mathrm{C}$. Fig. 4 shows the results of the experiment.

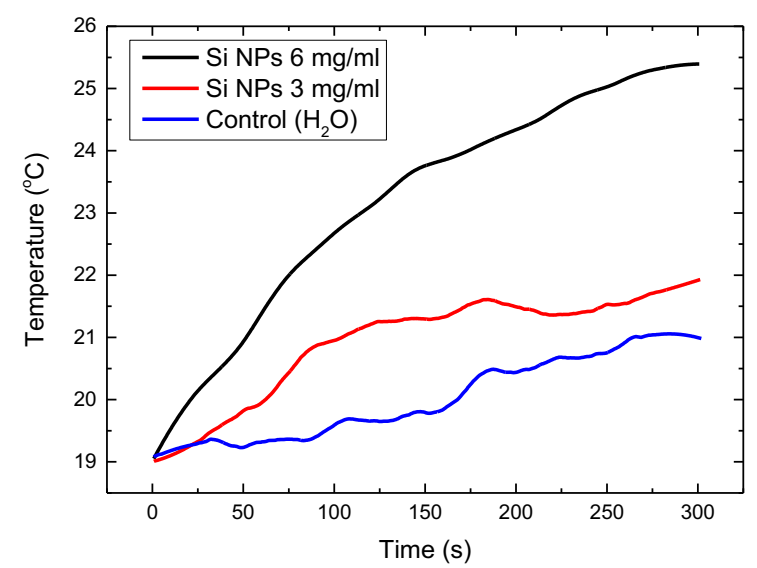

Fig. 4 Temperature relationship between the aqueous suspensions of microporous silicon with concentration of $6 \mathrm{~g} / \mathrm{l}, 3 \mathrm{~g} / \mathrm{l}$ and distilled water and the time of $27 \mathrm{MHz} \mathrm{HF}$ irradiation.

Conclusion: the final heating temperature grows with the $\mu \mathrm{PSi}$ particle concentration. Heating aqueous suspension of porous silicon nanoparticles of $3 \mathrm{~g} / \mathrm{l}$ concentration for $5 \mathrm{~min}$ leads to a $4{ }^{\circ} \mathrm{C}$ growth of the initial temperature, and to $7{ }^{\circ} \mathrm{C}$ growth at concentration of $6 \mathrm{~g} / \mathrm{l}$. The $\mathrm{HF}$ field radiation was used at $27 \mathrm{MHz}$ and $60 \mathrm{~W}$ power.

\subsection{Determination of the heating value of microporous silicon injected into beef liver under the influence of $\mathrm{HF}$ radiation \\ $(27 \mathrm{MHz})$}

The previous experiment has shown that as the concentration of microporous silicon increases, the temperature reached after $5 \mathrm{~min}$ of heating also increases. Now it is necessary to conduct an experiment with the concentration of micropore silicon HA, which will be effective in cancer therapy and yet low-toxic. This concentration was already calculated in Ref. [11] for the experiment with laboratory mice. The authors evaluated the physical parameters of mice, such as lethargy, weight loss, mortality, etc., when administering concentrations of HF solution from $150 \mathrm{mg} / \mathrm{ml}$ to $500 \mathrm{mg} / \mathrm{ml}$. As a result, only when a concentration of $150 \mathrm{mg} / \mathrm{ml}$ was administered, no side effects were seen, which allows us to assume that this concentration is the maximum possible concentration. However, in order to further reduce the risk of intoxication and to understand which concentration would allow sufficient heating to be achieved, we chose a concentration 10 times lower, $15 \mathrm{mg} / \mathrm{ml}$, for the experiment. It goes without saying that at higher concentrations, even greater heating will be achieved, as was established in the previous experiment.

Therefore, in this experiment, 15 grams of fresh beef liver were placed on a $6 \mathrm{~mm}$ plastic Petri dish. Two injection solutions were prepared for comparison. The first one was a $200 \mu \mathrm{l}$ aqueous solution of silicon nanoparticles with a concentration of $15 \mathrm{mg} / \mathrm{ml}$. The second was a $200 \mu$ l solution of distilled water. The $5 \mathrm{~min}$ heating was carried out by the UHF-60-MedTeKo UHFtherapy apparatus with the power of $60 \mathrm{~W}$. The results of the experiment are presented in Figs. 5 and 6.

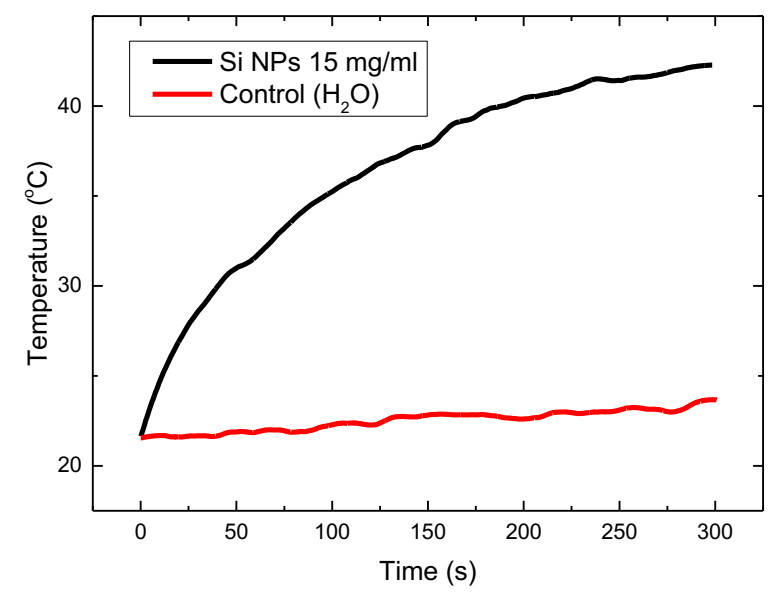

Fig. 5 Determination of the heating value under the influence of $\mathrm{HF}$ radiation $(27 \mathrm{MHz})$ of microporous silicon injected into beef liver. The graph of the temperature relationship between beef liver injected with nanoparticles of microporous silicon with a concentration of $15 \mathrm{mg} / \mathrm{ml}$ and distilled water and the time of exposure to $27 \mathrm{MHz} \mathrm{RF}$ radiation. 


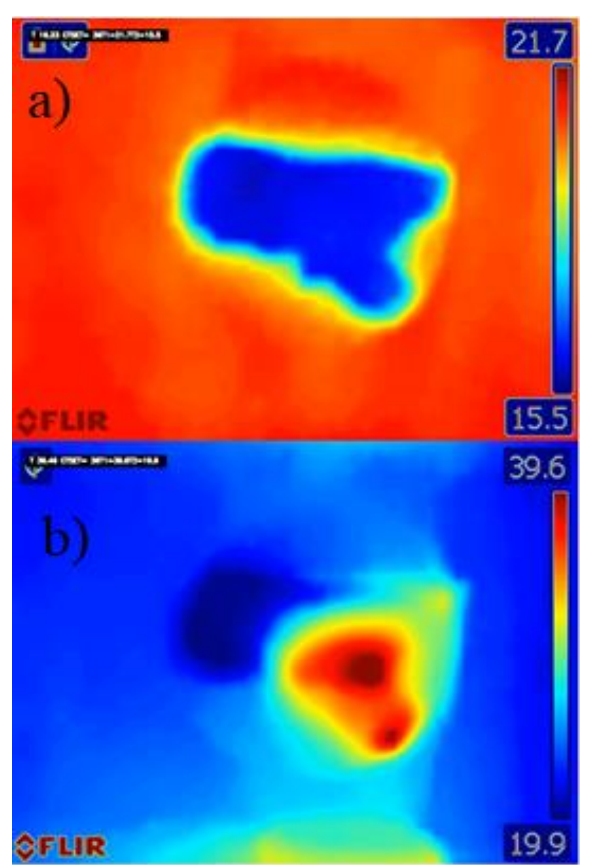

Fig. 6 Determination of the heating value under the influence of $\mathrm{HF}$ radiation $(27 \mathrm{MHz})$ of microporous silicon injected into beef liver. Images are taken from the thermal imaging camera. (a) Image of beef liver (blue area) before heating, its average temperature is about $20{ }^{\circ} \mathrm{C}$. (b) Image of the beef liver during the heating with the UHF machine for $4 \mathrm{~min}$. The temperature has already reached $39.6{ }^{\circ} \mathrm{C}$.

The figures show that at the injection site of microporous silicon nanoparticles, the temperature is much higher than in other areas and the difference is about $20^{\circ} \mathrm{C}$. This allows us to say that heating occurs only in the locations where microporous silicon nanoparticles are injected, while the adjacent zones are not affected. That is the main task of local hyperthermia: to heat only a narrow area of the affected tissues, without affecting the surrounding healthy ones.

Conclusion: as a result of experiments with silicon nanoparticles for 5 minutes of heating by the UHF-60MedTeKo device with a power of $60 \mathrm{~W}$, the temperature of $42{ }^{\circ} \mathrm{C}$ was reached, which is necessary for hyperthermia (the lower hyperthermia threshold of is $\left.41^{\circ} \mathrm{C}\right)$. At the same time, in the areas where the nanoparticles were not injected, the temperature was below $40{ }^{\circ} \mathrm{C}$ (which is the boundary temperature for healthy tissues, above which irreversible changes can occur).

\section{Conclusion}

In this work, the study of silicon nanoparticles as agents for UHF hyperthermia in vitro was carried out. On the basis of the experiments a number of conclusions were made:

1) Heating an aqueous suspension of porous silicon nanoparticles for 5 minutes with concentrations of $3 \mathrm{~g} / \mathrm{L}$ was $4{ }^{\circ} \mathrm{C}$ from the initial temperature and with concentrations of $6 \mathrm{~g} / \mathrm{L}$ was $7{ }^{\circ} \mathrm{C}$ in the $27 \mathrm{MHz}$ and $60 \mathrm{~W}$ RF field. As can be seen from the in vitro experiment, a $\mu \mathrm{Psi}$ nanoparticle solution with a concentration of $6 \mathrm{~g} / \mathrm{l}$ heated an average of 4 degrees more than the distilled water.

2) It was demonstrated that silicon particles could be used as sensitizers for local high-frequency hyperthermia. In an experiment with beef liver, the hyperthermia temperature of $42{ }^{\circ} \mathrm{C}$ was achieved in the accumulation zone of microporous silicon nanoparticles, while the adjacent around reached only a safe $20-25{ }^{\circ} \mathrm{C}$ temperature.

The experiments conducted show a great potential this research for cancer therapy. The next step in this direction will be to find the optimal concentration of nanoparticles, which will increase the effectiveness of therapy and yet reduce the toxicity. The second direction will be constructing a device for thermographic heating control during high-frequency hyperthermia. This device could bring the method of hyperthermia to a new level, allowing for high-quality and safe procedures in vivo.

\section{Disclosures}

All authors declare that there is no conflict of interests in this paper.

\section{Acknowledgements}

This research was supported by the UMNIK program of the Innovation Promotion Fund.

\section{References}

1. Y. V. Kargina, A. M. Perepukhov, A. Yu. Kharin, E. A. Zvereva, A. V. Koshelev, S. V. Zinovyev, A. V. Maximychev, A. F. Alykova, N. V. Sharonova, V. P. Zubov, M. V. Gulyaev, Y. A. Pirogov, A. N. Vasiliev, A. A. Ischenko, and V. Yu. Timoshenko, "Silicon Nanoparticles Prepared by Plasma-Assisted Ablative Synthesis: Physical Properties and Potential Biomedical Applications,” Physica Status Solidi (A) 216(14), 1800897 (2019).

2. Y. Zhang, M. Li, X. Gao, Y. Chen, and T. Liu, "Nanotechnology in cancer diagnosis: progress, challenges and opportunities," Journal of Hematology \& Oncology 12(1), 137 (2019).

3. K. Greish, "Enhanced Permeability and Retention (EPR) Effect for Anticancer Nanomedicine Drug Targeting," in Cancer Nanotechnology. Methods in Molecular Biology (Methods and Protocols), S. Grobnyer, B. Moudgil (Eds.), Humana Press, New Jersey, USA, 25-37 (2010). 
4. D. I. Bilenko, O. Y. Belobrovaya, V. V. Galushka, E. A. Zharkova, D. O. Kochnev, I. B. Mysenko, V. P. Polyanskaya, and D. V. Terin, "Porous silicon with AGI nanoparticles is a promising material for biomedical applications," Methods of computer diagnostics in biology and medicine, 201-203 (2015) [in Russian].

5. Hyperthermia (accessed 13 November 2020). [https://nmicr.ru/meditsina/vysokotekhnologichnaya-meditsinskayapomoshch/gipertermiya/].

6. L. A. Osminkina, V. Yu. Timoshenko, "Porous Silicon as a Sensitizer for Biomedical Applications," Mesoporous Biomaterials 3, 39-48 (2016).

7. K. P. Tamarov, L. A. Osminkina, S. V. Zinovyev, K. A. Maximova, J. V. Kargina, M. B. Gongalsky, Y. Ryabchikov, A. Al-Kattan, A. P. Sviridov, M. Sentis, A. V. Ivanov, V. N. Nikiforov, A. V. Kabashin, and V. Y. Timoshenko, "Radio frequency radiation-induced hyperthermia using Si nanoparticle-based sensitizers for mild cancer therapy," Scientific reports 4, 7034 (2014).

8. L. T. Canham, "Silicon quantum wire array fabrication by electrochemical and chemical dissolution of wafers," Applied Physics Letters 57(10), 1046-1048 (1990).

9. Transmission electron microscope LEO 912 ab omega (accessed 18 December 2020). [https://istina.msu.ru/equipment/card/29156772].

10. L. Sancey, S. Kotb, C. Truillet, F. Appaix, A. Marais, E. Thomas, B. van der Sanden, J.-P. Klein, B. Laurent, M. Cottier, R. Antoine, P. Dugourd, G. Panczer, F. Lux, P. Perriat, V. Motto-Ros, and O. Tillement, "Long-Term exvo Clearance of Gadolinium-Based AGuIX Nanoparticles and Their Biocompatibility after Systemic Injection," ACS Nano 9(3), 2477-2488 (2015). 